\title{
Triple NF-kB binding sites and LTR sequence similarities in HIV-1C isolates irrespective of helminth co-infection
}

\author{
Andargachew Mulu ${ }^{1,2^{*}}$, Melanie Maier ${ }^{1}$ and Uwe Gerd Liebert ${ }^{1}$
}

\begin{abstract}
Background: Helminth infections as well as structural alternations in the long-terminal repeat (LTR) regions of HIV-1 are known to contribute to elevated HIV RNA level and enhance HIV-1 diseases progression. However, the impact of helminths infections on the occurrences of triple NF-KB and genetic variability in LTR region of HIV-1C isolates is not known. We aimed to examine the presence of genetic variability in the LTR region of HIV-1C isolates during chronic HIV-helminth co-infection.
\end{abstract}

Methods: HIV-1C infected Ethiopians with $(n=22)$ and without $(n=20)$ helminth infection were included. The LTR region of HIV was amplified and sequenced. Sequences were aligned with reference set from the Los Alamos HIV database. Phylogenetic analysis and frequency of polymorphic changes was performed by the neighbour-joining method using Geneious Basic software.

Results: All LTR sequences from patients with or without of helminth co-infection clustered with HIV-1 subtype C with two distinct subclusters ( $C$ and $\left.C^{\prime}\right)$. The enhancer element was found to have three copies of 10-base pair binding sites for NF-KBs which is an evidence for predominance of triple NF-KB sites (94\%) in HIV-1C isolates irrespective of helminths co-infection and subclusters. Moreover, irrespective of helminth co-infection and $\mathrm{C}^{\prime} \mathrm{C}^{\prime}$ subclusters high sequences similarity in LTR was observed. There was no significant difference in plasma HIV RNA level between HIV-1 $C$ and $C^{\prime}$ subclusters.

Conclusions: Despite the small sample size, the predominance of triple NF-KB binding sites and high sequence similarities in LTR region irrespective of helminths infection suggest the natural occurrence of the three NF-KB binding sites in HIV-1C isolates without the influence of secondary infection. Thus, the higher HIV-1C viraemia in helminth co-infected individuals is more likely a result of immune activation rather than LTR sequence variation. Moreover, the lack of significant difference in plasma HIV RNA level between HIV-1 C and C' subcluster may show the lack of functional differences among the two groups.

Keywords: NF-KB, LTR sequences, HIV-1 C/C' subclusters, Helminths, HIV viral load

\section{Background}

According to UNAIDS report, half of the people infected with HIV-1 in sub Saharan Africa are estimated to be co-infected with helminths [1] which may accelerate the course of HIV by augmenting viral replication [2,3]. Immunologic evidence on the mechanisms by which chronic helminth infection may facilitate HIV-1 replication in

\footnotetext{
* Correspondence: andargachewmulu@yahoo.com

'Institute of Virology, Leipzig University, Johannisallee 30, Leipzig 04103, Germany

${ }^{2}$ Department of Microbiology, College of Medicine and Health Sciences, University of Gondar, Gondar, Ethiopia
}

co-infected individuals is well documented [4]. It is suggested that HIV/helminths co-infected patients experience a shift from a Th1 to a predominantly Th2 response [4-6]. Consecutively, it has been speculated that chronic immune activation and the presence of a dominant Th2 cytokine environment may increase the risk of acquiring HIV infection [6,7]. The chronic immune activation has been proposed as the main cause for elevated plasma HIV RNA level reported among sub Saharan Africa patients [8]. The role of intestinal helminth coinfection and deworming on HIV viral load among acute 
sero-converters is controversial [9-12]. During chronic HIV-1 infection there is a sustained and dramatic immune activation characterized by elevated plasma levels of TNFalpha, IL-1, and IL-6, which is directly correlated with plasma HIV RNA levels [13]. We have recently observed higher HIV-1C viraemia in chronically helminthic coinfected patients, which was significantly reduced after 12 weeks of deworming [14].

Indeed, viral factors and their interaction with host factors also indicate the risk of HIV disease progression, elevated plasma HIV RNA level, and higher HIV transmission rate reported among sub Saharan African patients [13,15]. For example, HIV-1 long-terminal repeat (LTR) is known to regulate viral gene expression by interacting with multiple viral and host factors. Reports on the contribution of structural alterations in the LTR region to disease progression and higher HIV transmission rate are controversial. Intracellular parasitic infection like Leishmania was found to be a potential activator for HIV replication and potent inducer of LTR transcription and viral replication in vitro. Moreover, the transcription factor NF- $\mathrm{kB}$ in the enhancer region of the LTR is activated through infection with viral and other pathogens independently [16]. Activation of HIV-1 LTR transcription in host cells through complex biochemical pathways involving the participation of transcriptional factor NF- $\mathrm{kB}$ has been observed during leishmania parasite co-infection in vitro [16]. The sequence of the enhancer element varies among HIV-1 subtypes [17]. Triple NF-kB sequences have been described in most HIV-1C isolates [18-20] and believed to influence the viral fitness and higher replication and transmission. However, the relationship between the occurrences of triple NF-kB in most HIV-1C isolates and helminths co-infection is not known. During chronic HIV-1 infection with helminth co-infection, the ensuing immunological imbalance could conceivably lead to increased expression of co-receptor and transcriptional factors resulting in higher HIV RNA level and faster disease progression which may in turn result in active up-regulation of HIV LTR. Such functional shifts could be a result of structural alteration on the transcriptional factor NF-kB. We hypothesise that the higher HIV RNA level in helminths co-infected patients may also be associated with sequence alterations in LTR region [14]. Thus, the aim of the current study was to examine the impact of helminths on genetic variability on LTR region of HIV-1 during chronic HIV-helminth co-infection.

\section{Methods}

This study was aimed to investigate the effect of helminths infection on the presence of alterations in regions and motifs of LTR during chronic HIV-helminths infection. The details of patient inclusion were described previously [14]. Briefly, symptomatic HIV-infected persons above 18 years of age, seeking treatment and willing to participate were evaluated with a standardized form at enrolment. Patients were excluded for the following reasons or conditions: pregnancy, treatment with single dose nevirapine for prevention of mother-to-child transmission of HIV or any other antiretroviral therapy (ART), known diabetes, hypertension, epilepsy, liver, cardiac and renal diseases, genital ulcer or active tuberculosis at enrolment. T-cell count was made using flow cytometer (FACSCount, Becton Dickinson, San Jose, California, USA) following the manufacturer's protocol. Plasma HIV-1 RNA level was determined by quantitative real time PCR (Abbott m2000rt instrument, Abbott Molecular, Des Plaines, IL, USA). The lower detection limit of the assay was 40 copies/ml (1.6 $\log _{10}$ RNA copies/ml).

The LTR region was amplified by nested PCR using a published protocol [18]. Nucleic acid sequencing was performed using the inner primers and the ABI prism 310 Dye Terminator Cycle Sequencing Kit according to the manufacturing instruction (Applied Biosystems, Foster City, CA, USA). Sequences were aligned with reference set from the Los Alamos HIV database (www.hiv.lanl.gov). Phylogenetic analysis was performed by the neighbourjoining method with 1,000 bootstrap replicates under Kimura's two-parameter correction using Geneious Basic software (http://www.geneious.com). The frequency of polymorphic changes (number of nucleotide changes found in each consensus sequence with respect to ETH2220 reference sequence divided by the total number of nucleotides sequenced) was calculated for enhancer, promoter regions and TRA elements of the LTR regions relevant for transcription.

\section{Results}

The baseline demographic data (Table 1), baseline differences in plasma HIV RNA level and T cell counts and the impact of helminth co-infection on HIV-1 viraemia and its dynamics before and 12 weeks after deworming (Figure 1) were described previously [14]. The mean plasma HIV RNA level at baseline was $4.30 \pm 1.09 \log _{10}$ RNA

\begin{tabular}{|c|c|c|c|}
\hline Variables & $\begin{array}{l}\text { With helminths } \\
(n=87)\end{array}$ & $\begin{array}{l}\text { Without helminths } \\
(n=133)\end{array}$ & $P$ value \\
\hline \multicolumn{4}{|l|}{ Sex } \\
\hline Male & 42 & 50 & n.a. \\
\hline Female & 45 & 83 & n.a. \\
\hline Age $($ Mean + SD) & $31.4 \pm 9^{a}$ & $33.7 \pm 8$ & n.a. \\
\hline $\log _{10}$ HIV RNA (copies/ml) & $4.83 \pm 0.85$ & $3.95 \pm 0.96$ & $<0.001$ \\
\hline $\mathrm{CD}^{+}{ }^{+} \mathrm{cell} / \mathrm{mm}^{3}$ & $214 \pm 142$ & $212 \pm 160$ & 0.944 \\
\hline $\mathrm{CD}^{+} \mathrm{T}$ cell $/ \mathrm{mm}^{3}$ & $970 \pm 566$ & $893 \pm 427$ & 0.035 \\
\hline
\end{tabular}

n.a: Not applicable; ${ }^{a}$ Mean \pm SD. 


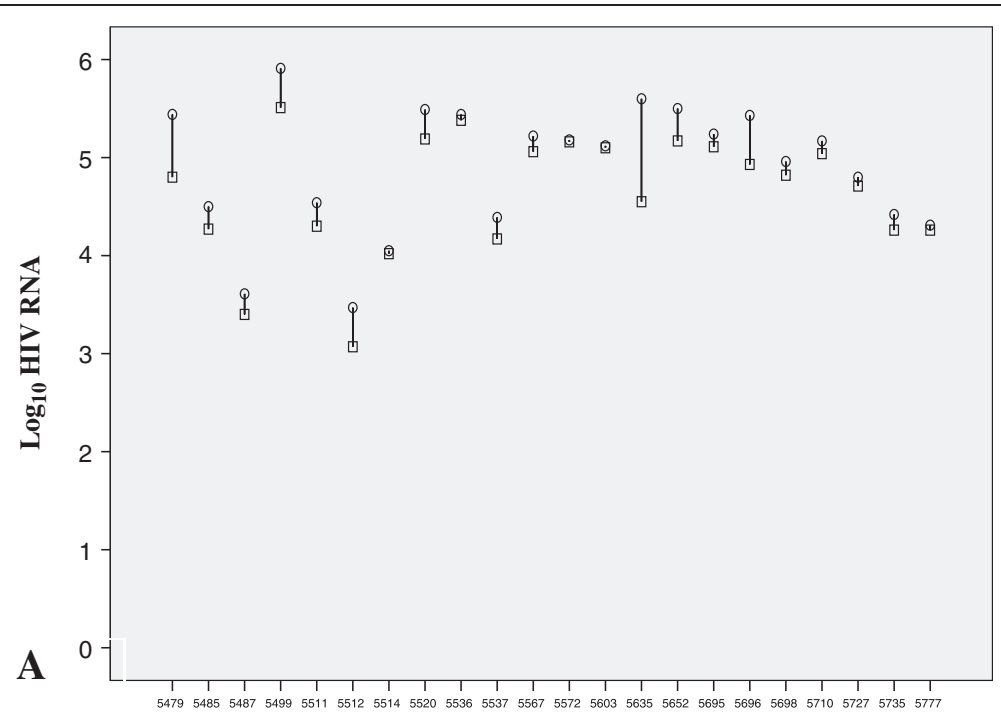

Patients ID

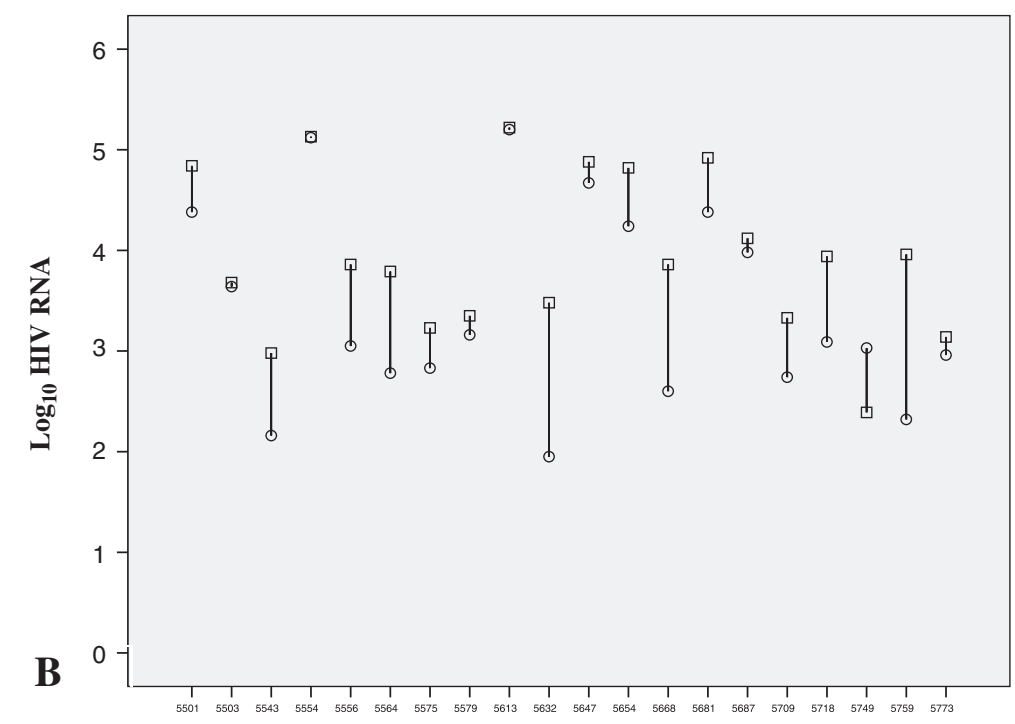

Patients ID

Figure 1 Dynamics of plasma HIV RNA level of each patient with (A) and without (B) helminths infection at baseline (circles) and after 12 weeks of administration of antihelminthic drugs (squares).

copies/ml. There were no difference in plasma HIV RNA level $(\mathrm{P}=0.7)$ among females and males. However, plasma HIV RNA level was significantly higher $(4.83 \pm 0.9$ versus $3.95 \pm 1.0 \log _{10}$ HIV RNA copies/ml) in individuals coinfected with intestinal parasites than in those without (Table 1). There was a mean decrease in plasma HIV level $\left(-0.3 \log _{10} \pm 0.83\right)$ after successful treatment of helminths, but an increase in HIV load in patients that had no helminth coinfection (Figure 1) in parallel with significant reduction in $\mathrm{CD}^{+} \mathrm{T}$ cells.

Phylogenetic analysis revealed that all LTR sequences from patients with and without helminths co-infection were clustered within HIV-1 subtype C (Figure 2) concordant with the respective protease and reverse transcriptase sequences of HIV-1 genome [21]. However, two distinct sub-clusters $\left(\mathrm{C} / \mathrm{C}^{\prime}\right)$ with bootstrap values of less than $65 \%$ were observed (Figure 2). The $\mathrm{C}$ subclusters which is related to the Ethiopian reference strain (ETH2220) were higher than the C' subclusters which possesses phylogenic links to the strains circulating in southern Africa (63.6 versus 22.7\%). Three of the 22 (13.6\%) isolates could not be classified in either one of the two subclusters. Irrespective of helminths infection and $\mathrm{CD} 4{ }^{+} \mathrm{T}$ cell count, there was no significant difference 


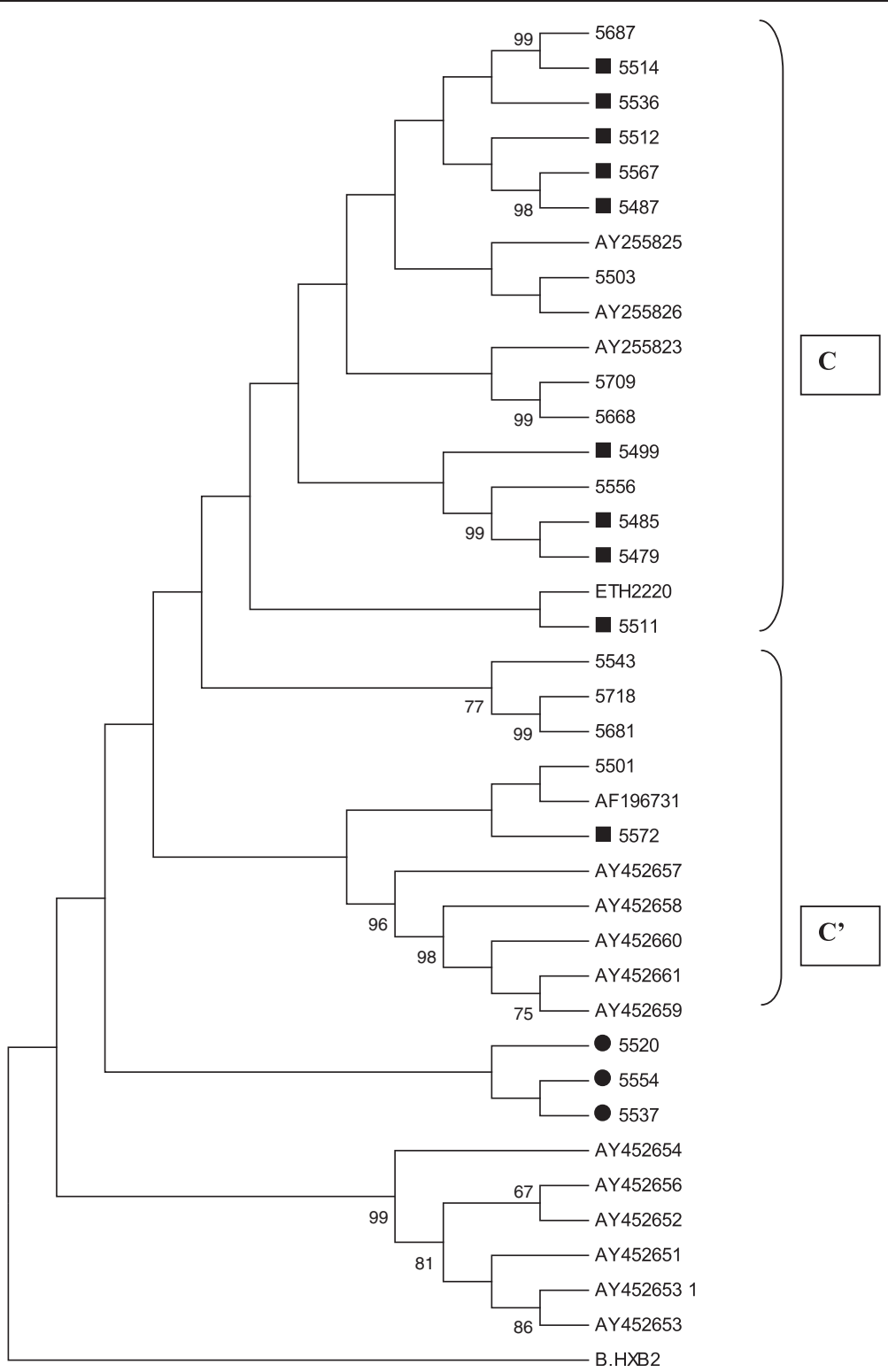

Figure 2 Phylogenetic tree of LTR sequences from chronically infected patients with and without helminths coinfection (Current isolates are designated by 4 digit numbers and the rest are reference sequences). The two genotypes cocirculating are indicated as $C$ and $C^{\prime}$. Keys: Sequences with Black Square $(\boldsymbol{\bullet})$ are from patients with chronic helminths infection and with Black circles $(\bullet)$ are isolates which could not be classified in either one of the two subclusters.

in plasma HIV RNA level at baseline and 12 weeks after deworming (4.42 \pm 0.6 versus $4.33 \pm 0.7 \log _{10}$ HIV RNA copies/ml; $4.12 \pm 0.8$ versus $4.22 \pm 1.0 \log _{10}$ HIV RNA copies/ml) between in HIV-1 C and C' subclusters, respectively. This observation remained the same after $\mathrm{CD}^{+} \mathrm{T}$ cell counts was stratified as low $\left(<200\right.$ cells $\left./ \mathrm{mm}^{3}\right)$, medium 201-350 cells $\left./ \mathrm{mm}^{3}\right)$ and high $\left(>350 \mathrm{cell} / \mathrm{mm}^{3}\right)$.

The enhancer element was found to have three copies of 10-base pair binding sites for NF- $\mathrm{kB}$ which is an evidence for predominance of triple NF- $\kappa B$ sites $(94 \%)$ of the isolates with only one isolate having two NF- $\mathrm{kB}$ sites (with deletion of 11 nucleotides). No significant differences were observed in the mutation/polymorphic frequency in most LTR regulatory sites among patients with and without helminths co-infection (Table 2, Figure 3) and among $C$ and C' subclusters. Briefly, the core region of the LTR which is composed of the TATAA box (29-24 nucleotides) upstream of the transcriptional start site, and specificity protein $(\mathrm{Sp})$ binding sites which are three tandem GC-rich binding sites interacting with transcription factors SpI to SpIII were the most conserved regions. Moreover, SpII site of the promoter region was identical 
Table 2 LTR genetic variability on transcriptional and regulatory sites in HIV-1 subtype C chronically infected individuals with and without helminths coinfections

\begin{tabular}{|c|c|c|c|c|c|c|c|c|c|c|}
\hline \multirow[t]{3}{*}{ Variables } & \multicolumn{10}{|c|}{ Mutation frequency $\left(\times 10^{-2}\right)^{a}$} \\
\hline & \multicolumn{3}{|c|}{ Enhancer region } & \multicolumn{5}{|c|}{ Promotor region } & \multicolumn{2}{|c|}{ TAR element } \\
\hline & NF-kBI & NF-кBII & NF-кBIII & SPI & SP II & SP III & E-box I & TATA box & E-box II & TAR \\
\hline With helminths infection & 8.5 & 12.4 & 2.6 & 12.4 & 0 & 8.8 & 2.5 & 3.1 & 1.7 & 7.1 \\
\hline Without helminths infection & 9.3 & 11.3 & 1.6 & 14.1 & 0 & 5.3 & 5.0 & 2.7 & 1.7 & 7.7 \\
\hline
\end{tabular}

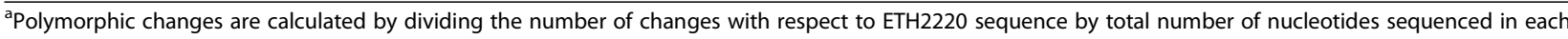
region; NF-KB-Nuclear factor Kappa B; TAR element-Transcription trans-activator.

in both groups of patients. The TATAA box, which binds TATAA-binding protein in association with a number of other proteins was the second most identical region. Six closely related monophyletic groups with bootstrap value of $99 \%$ (Figure 2) were also observed which is concordant with their respective pol genome [21].

\section{Discussion}

This is the first study, which examines the genetic variability of HIV-1C LTR region among chronically infected patients with and without helminths co-infection. The findings of LTR high genetic similarity in most of the regulatory sites irrespective of helminths co-infections may suggest the compensation of immunological imbalance $[4,13,16,18]$ which could be induced by both chronic HIV and helminths infections. Sequence inconsistency in the LTR binding sites (the promoter, enhancer, modulatory and TAR regions) have been observed in other subtypes. Nevertheless, it remains unclear for the majority of the clades that whether the observed sequence differences could influence the replicative capacity of the subtypes $[16,17]$. The predominance of triple NF- $\mathrm{kB}$ sites in the current Ethiopian isolates is similar with previous studies from Africa and the rest of the world where subtype C is predominately circulating [17-20]. The occurrence of triple NF- $\kappa B$ sites with and without helminths infection shows the lack of association between helminths infection and presence of the third NF- $\mathrm{kB}$ sites; and is an additional evidence for the natural occurrence of triple NF- $\mathrm{kB}$ sites in HIV-1C isolates $[17,19]$, irrespective of co-infection. Thus, the biological influence of helminths could not directly determine genetic variability or similarity, suggesting that the observed high level of HIV-1C viraemia during chronic HIV-helminth co-infection [4,6,9-12,14] is due to the immune activation $[4,8]$. Although deletion of one or two NF- $\mathrm{kB}$ sites leads to substantially decreased replication levels [20], the subject 5627 (Figure 3) in the current study with deletion of the second NF- $\mathrm{kB}$ sites

\begin{tabular}{|c|c|c|c|c|}
\hline & & Enhancer region & Promotor region & \multirow[t]{2}{*}{ TAR element } \\
\hline & $\mathrm{NF}-\kappa \mathrm{BI}$ & NF-кBIII & TATA E-boxII & \\
\hline 1. Етн2. & AGGPACATCCGGAGTATTACAAAGACTGCTGACACAGA GG & SACRTTCCGCUGGACTRTCCACTGGGGCGTTS & CCAGGAGGAGGGGTCTGGGCGGGACTGGGAGTGGCAACCCTCAGATGCTGCATATAAGCAGCTGC! & CTGCATATAAGCAGCTGCTTTTCGCTTG \\
\hline 2.5118 & IAGCTACATCCGGAGTMTACAAAGACTGCTGACACAGAAGG & GACRTTCCGCTGGGACTRTCCACTGGGGCGTTi & CCAGGAGGGMGGPTGGGCGGGACTGGGAGTGGCCAGCCCRCAGATGCRGCATAPAAGCAGCTGC! & CTGCATATAAGCAGCTGCTTTTGGTTG \\
\hline 3.5709 & :AGCTACATCCGGAGPATIACAAAGACTGCTGACACAGAAGG & GACTRTCCGCTGGGACTRTCCACTGGGGCGTR & CCAGMGGGAGMGTCTGGGCGGGACGGGGAGTGGCMACCCTCAGATGCTGCATATAAGCAGCTGC! & CTGCATATAAGCAGCTGCTTTTCGCTTG \\
\hline 4.5687 & AAGCTACATCCGGAGTATIACAAGACTGCTGACACAGUGG & GACRTTCMGTGGGACTRTCCACTGGGGCGMTS & CCAGGAGGAGMGTCTGGGCGGGACTGGGAGTGGCCAACCCTCAGATGCTGCATATAAGCAGCTGE' & CTGCATATAAGCAGCTGMTITTCGTTG \\
\hline 5.5681 & :AGCTACATCCGGAGTMITACAAAGACTGCTGACACAGAAGG & GACRTTCCGCTGGGACTRTCCACTGGGGCGTR & 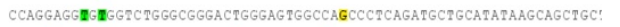 & CTGCATATAAGCAGCTGCTITTCGCTTG \\
\hline 6.5668 & :AGCTACATCCGGAGTATTACAAAGACTGCTGACACAGAAGG & GACRTTCCGCTGGGACTRTCCACTGGGGCGTT & CCAGMGGGAGMGTCTGGGCGGGACAGGGAG TGGCMAACCCRCAGATGCRGCATATAAGCAGCTGC! & CTGCATATAAGCAGCTGCTTTTCGCTTG \\
\hline 7.5572 & :AGCTACATCCGGAGTAMIACAAAGACTGCTGACACAGAAGG & GACMTTCCGCTGGGATITRCCACTGGGGCGTM & CCAGGAGGAG-GGICTGGGCGGGACGGGGAGTGGCCAACCCTCAGATGCTGCATARAAGCAGCTGE! & CTGCATARAAGCAGCTGMIITIMGCUTG \\
\hline 8.5567 & AAGCTACATCCGGAGTATYACAAAGACTGCTGACACAGAAGG & GACTRTCCGCTGGGACTRTCCACTGGGGCGTR & CCAGGAGGAGMGTCTGGGCGGGACTGGGAGMGGCWAACCCTCAGATGCPGCATATAAGCAGCTGC! & CTGCATATAAGCAGCTGCTTITCGCWTG \\
\hline 9.5556 & :AGCTACATCCGGAGIWIACAAAGACTGCIGACACAGAAGG & GACRTTCCGCTGGGACT TRCCACTGGGGCGMT & 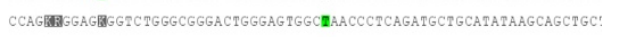 & CTGCATATAAGCAGCTGCTTTTCGCUG \\
\hline 10.5554 & :AGCTACATCCGGAGTATTACAAAGACTGCTGACACAGAAGG & 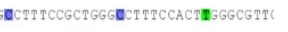 & 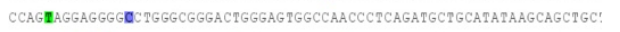 & CTGCATATAAGCAGCTGCTTITCGCTTG \\
\hline 11.5543 & :AGCTACATCCGGAGITIACAAAGACTGATGACACAGAAGG & SACRTPCCGCGGGACTRCCACTGGGGGMT & CCAGGAGGWGGTCTGGGCGGGACGGGAGTGGCCAGCCCTCAGATGCTGCATATAAGCAGCTGC! & CTGCATATAAGCAGCTGCTTITCGCTG \\
\hline 12.5537 & LAACTACATCCGGAGACAAGAAAGACTGCTGACACAGAAGG & GACRTTCCGCTGGGACTRTCCACTGGGGCGTR & CCIGGAGGWGGGICTGGGCGGGACGGGAGTGGCCAGCCCTCAGATGCTGCATATAAGCAGCTGC! & CTGCATATAAGCAGCTGCTITTCGCTG \\
\hline 13.5536 & AAGCTAMTCCGGAGATTACAAAGACTGCTGACAGAAGG & 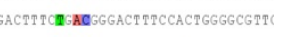 & CCAGGAGGAGGGTCTGGGCGGGACGGGAGTGGCAACCCTCAGATGCTGCATATAAGCAGCTGC! & CTGCATATAAGCAGCTGCTTTTCGCTTG \\
\hline 14.5520 & AAGCTACATCCGGAGPATACAAGACTGCTGACACAGAAGG & GACRTRCCGCTGGGACTRPCCM GGGGCGTR & CCAGGAGGAGGGGTCTGGGCGGGACTGGGAGGAGCCAACCCTCAGATGCPGCATATAAGCAGCTGC! & CTGCATATAAGCAGCTGCTTTTCGCTIG \\
\hline 15.5514 & :AGCTACATCCGGAGTATPACAAIGACTGCTGACACAG & GACMTTMCTGGGACTRCCACTGGGGCGTM & CCAGGAGGAGMGTCTGGGCGGGACTGGGAGTGGCCAACCCPCAGATGCTGCATACAGCAGCTGC! & CTGCATACAGCAGCTGCTTTTCGTTG \\
\hline 16.5512 & :AGCTACATCCGGAGTATRACAAAGACTGCTGACACAGAAGG & GACTMTCCGCTGGGACRTRCCACTGGGGCGTTI & CCAGGAGGAGGAGPCTGGGCGGGACTGGGAGTGGCCAACCCICAGATGCPGCATATAAGCAGCTGC! & CTGCATATAAGCAGCTGCTTTTCGCTTG \\
\hline 17.5511 & :AGCTACATCCGGAGMTYACAAAGACTGCTGACACAGAAGG & SACRTTCCACTGGGACT TRCCGCTGGGGCGTR & CCAGGAGGAG $G$ GCTGGGCGGGACAGGGAGTGGCCAGCCCTCAGATGCPGCATATAAGCAGCG! & CTGCATATAAGCAGCUGCTTTCGCTG \\
\hline 18.5503 & LAGCTACATCCGGAGMTYACAARACTGCTGACACMAAGG & 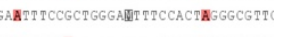 & CCAGGGGGAG GTCTGGGCGGGACTGGGAGTGGCCAACCCTCAGATGCTGCATATAAGCAGCTGC! & CTGCATATAAGCAGCTGCTTITCGCTTG \\
\hline 19.5501 & :AGCTACATCCGGAGTGGIACAAAGACTGCTGACACAGAAGG & SACTITCCA--------CCACTGGGGCGTTi & CCAGGAGGGGGGTC TGGGCGGGAC & \\
\hline 20.5499 & AAGCTACATCCGGAGTAVIACAAAGACTGCTGACACAGAAGG & CMTRCCGCOGGACRTCCACRGGGCGRTI & 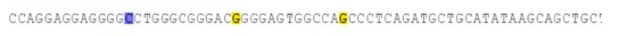 & CTGCATATAAGCAGCTGCTITMGCUG \\
\hline 21.5487 & :AGCTACATCCGGAGTAMTACAAAGACTGCTGACACAGAAGG & GACRTTCCGCTGGGACTRTCCACTGGGGCGTTi & 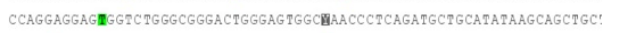 & CTGCATATAAGCAGCTGCTITTCGCTG \\
\hline 22.5485 & AAGCTACATCCGGAGIWIACAAAGACTGCTGACACAGAAGG & GACTTTCCGCTGGGACT TRCCACTGGGGCGTM & CCAGGGGGAGGGGRCTGGGCGGGACTGGGAG MGGMAACCCRCAGATGCTGCATATAAGCAGCTGC! & CTGCATATAAGCAGCTGCITTTCGCTG \\
\hline 23.5479 & :AGCTACATCCGGAGMIAMAAARACTGCTGACACAGAAGG & GACRTTCCGCTGGGACT TRCCACTGGGGCGTR & 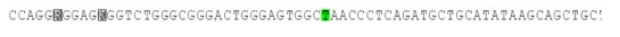 & CTGCATATAAGCAGCTGCTTTTCGCTG \\
\hline \multicolumn{5}{|c|}{$\begin{array}{l}\text { Figure } 3 \text { Sequences of most enhancer, promoter region and LTR element of isolates with and without helminths coinfection with } \\
\text { respect to ETH } 2220 \text { consensus reference. Sequences of } 5572,5567,5537,5536,5520,5514,5512,5511,5499,5487,5485 \text { and } 5479, \text { are } \\
\text { patients with chronic helminths infection. Sequences of 5543,5718,5681, } 5501 \text { and } 5572 \text { are HIV-1C' subclusters. Keys: NF-KB-Nuclear factor } \\
\text { Kappa B; TAR element-Transcription trans-activator. }\end{array}$} \\
\hline
\end{tabular}


(11 nucleotides) had comparable HIV RNA level with the rest of the subject. Indeed, the function of this additional site may be altered during co-infection because of the immune dysregulation or activation.

Previous studies in Ethiopia showed the presence of two distinct subtypes $\mathrm{C}$ subclusters $\left(\mathrm{C}\right.$ and $\mathrm{C}^{\prime}$ ) based on phylogenetic analysis of the env region [22-27] and the increasing of subcluster C' overtime [23] although the epidemic of both strains began around the same time [25]. The separate cluster of the LTR sequences from these chronically infected patients in the current study compared with Ethiopian reference isolates (ETH2220) strengthen previous studies that demonstrated that the Ethiopian subtype $\mathrm{C}$ had a genetic subcluster designated $\mathrm{C}^{\prime}$ in the $L T R$ regions [22-27]. The genetic subclusters may indicate a different introduction of HIV in to Ethiopia [23] and diversity of the circulating HIV-1 C subtypes in the country. Although, the prevalence of C' was increasing from $48 \%$ in 1988 to $70 \%$ in 1997 based on env gene [23,26], indicating that C' viruses may be spreading faster in Ethiopia, we found a higher $C$ subcluster compared with $C^{\prime}$ similar with previous report from central Ethiopia [27] indicating that when considering the LTR sequence the one from the C genotype may be advantageous in northwest Ethiopia. Unlike previous report [26], in the current study lack of significant difference in plasma HIV RNA level between HIV$1 \mathrm{C}$ and C' subcluster was observed and may show the lack of functional differences among the two groups. The 63.6\% HIV-1 C subcluster in northwest Ethiopia is additional epidemiological evidence which demonstrates that subcluster $\mathrm{C}$ has deep rooted and is the predominant genotype currently circulating in northwest Ethiopia.

\section{Conclusions}

Despite the small sample size, the predominance of triple $\mathrm{NF}-\mathrm{KB}$ sites and high sequence similarities in most LTR regions irrespective of helminths co-infection suggest the natural occurrence of additional NF- $\mathrm{kB}$ sites in HIV-1C isolates without the influence of helminths infection. Thus, the higher HIV-1C viraemia in helminth coinfected individuals is more likely a result of immune activation rather than LTR sequence variation. The lack of significant difference in plasma HIV RNA level between HIV-1 C and C' subcluster may show the lack of functional differences among the two groups. However, it needs further studies to describe the role of HIV-1 C/C' genetic variants in HIV-1 immunopathogenesis.

\section{Competing interests}

The authors declare that they have no competing interest.

\section{Authors' contributions}

All authors participated in the design, analysis, and interpretation of the study and writing the manuscript. All authors read and approved the final manuscript.

\section{Acknowledgement}

The authors would like to thank all study participants. Expert technical assistance by Sandra Bergs and Janka Rätzke is gratefully acknowledged.

\section{Funding}

This work was supported by German Academic Exchange Service (DAAD), Association of Sponsors and Friends of Leipzig University, and HIV/AIDS Prevention and Control Office of Amhara Regional State, Ethiopia.

Received: 24 February 2014 Accepted: 25 April 2014

Published: 29 April 2014

\section{References}

1. UNAIDS: Epidemic Update. 2010. http://www.unaids.org/globalreport/.

2. Bentwich Z, Weisman Z, Grossman Z: Pathogenesis of AIDS in Africa-lessons from the Ethiopian immigrants in Israel. Immunologist 1997, 5:211-216.

3. Lawn SD, Butera ST, Folks TM: Contribution of immune activation to the pathogenesis and transmission of human immunodeficiency virus type 1 infection. Clin Microbiol Rev 2011, 14:753-757.

4. Bentwich Z, Maartens G, Torten D, Bar-Yehuda, Kalikovich A: Concurrent infections and HIV pathogenesis. AIDS 2071-2081, 12000:4

5. Kassu A, Tsegaye A, Wolday D, Petros B, Aklilu M, Sanders EJ, Fontanet AL, Van Baarle D, Hamann D, De Wit TF: Role of incidental and/or cured intestinal parasitic infections on profile of $\mathrm{CD} 4+$ and $\mathrm{CD}^{+}{ }^{+}$cell subsets and activation status in HIV-1 infected and uninfected adult Ethiopians. Clin Exp Immunol 2003, 132:113-119.

6. Borkow G, Bentwich Z: HIV and helminth co-infection: is deworming necessary? Parasite Immunol 2000, 28:605-612.

7. Morgan D, Whitworth J: The natural history of HIV-1 infection in Africa. Nat Med 2001, 7:143-145.

8. Bentwich Z, Kalinkovich A, Weisman Z, Borkow G, Beyers N, Beyers A: Can eradication of helminthic infections change the face of AIDS and tuberculosis? Immunol Today 1999, 20:485-487.

9. Wolday D, Mayaan S, Mariam ZG, Berhe N, Seboxa T, Britton S, Galai N, Landay A, Bentwich Z: Treatment of intestinal worms is associated with decreased HIV plasma viral load. J Acquir Immune Defic Syndr 2002, 31:56-62.

10. Modjarrad K, Zulu I, Redden DT, Njobvu L, Lane HC, Bentwich Z, Vermund SH: Treatment of intestinal helminths does not reduce plasma concentrations of HIV-1 RNA in coinfected Zambian adults. J Infect Dis 2005, 192:1277-1283.

11. Hosseinipour MC, Napravnik S, Joaki G, Gama S, Mbeye N, Banda B, Martinson F, Hoffman I, Cohen MS: HIV and parasitic infection and the effect of treatment among adult outpatients in Malawi. J Infect Dis 2007 195:1278-1282.

12. Walson JL, Herrin BR, John-Stewart G: Deworming helminth co-infected individuals for delaying HIV disease progression. Cochrane Database Syst Rev 2009, 3:CD006419. doi:10.1002/14651858.CD006419.pub3.

13. Graziosi C, Soudeyns H, Rizzardi PG: Immunopathogenesis of HIV infection. AIDS Res Hum Retroviruses 1998, 14:S135-S142.

14. Mulu A, Maier M, Liebert UG: Deworming of intestinal helminths reduces HIV-1 subtype C viremia in chronically co-infected individuals. Int J Infect Dis 2013, 17:e897-e901.

15. Alemu A, Shiferaw Y, Addis Z, Mathewos B, Birhan W: Effect of malaria on HIV/AIDS transmission and progression. Parasites \& Vectors 2013, 6:18. doi:10.1186/1756-3305-6-18.

16. Olivier M, Badaró R, Medrano FJ, Moreno J: The pathogenesis of Leishmania/HIV co-infection: cellular and immunological mechanisms. Ann Trop Med Parasitol 2000, 97:S79-S98.

17. Arellano Eva R, Soriano V, Alcami J, Holguin A: A new finding on the transcription regulation across different subtypes. AIDS Rev 2006, 8:9-16.

18. De Baar MP, De Ronde A, Berkhout B, Cornelissen M, Van Der Horn KH, Van Der Schoot AM, De Wolf F, Lukashov W, Goudsmit J: Subtype-Specific Sequence Variation of the HIV Type 1 Long Terminal Repeat and Primer-Binding Site. AIDS Res Hum Retroviruses 2000, 16:499-504.

19. Jeeninga RE, Hoogenkamp M, Armand-Ugon M, De Baar M, Verhoef K, Berkhout B: Functional Differences between the Long Terminal Repeat Transcriptional Promoters of Human Immunodeficiency Virus Type 1 Subtypes A through G. J Virol 2000, 74:3740-3751.

20. Bachu M, Yalla S, Asokan M, Verma A, Neogi U, Sharma S, Murali RV Mukthey AB, Bhatt R, Chatterjee S, Rajan RE, Cheedarla N, Yadavalli VS, Mahadevan A, Shankar SK, Rajagopalan N, Shet A, Saravanan S, Balakrishnan P, Solomon S, Vajpayee M, Satish KS, Kundu TK, Jeang KT, Ranga U: Multiple 
NF-KB sites in HIV-1 subtype C LTR confer superior magnitude of transcription and thereby the enhanced viral predominance. J Biochem 2012, http://www.jbc.org/cgi/doi/10.1074/jbc.M112.397158.

21. Mulu A, Lange T, Liebert UG, Maier M: Clade homogeneity and Pol gene polymorphisms in chronically HIV-1 infected antiretroviral treatment naive patients after the roll out of ART in Ethiopia. BMC Infect Dis 2014, 14:158. Doi: 10.1186/1471-2334-14-158.

22. Kassu A, Fujino M, Matsuda M, Nishizawa M, Ota F, Sugiura W: Molecular epidemiology of HIV-1 in treatment naive patients in North Ethiopia. AIDS Res Hum Retroviruses 2007, 23:564-568.

23. Pollakis G, Abebe A, Kliphuis A, De Wit TF, Fisseha B, Tegbaru B, Tesfaye G, Negassa H, Mengistu Y, Fontanet AL, Cornelissen M, Goudsmit J: Recombination of HIV type $1 C\left(C^{\prime} / C^{\prime \prime}\right)$ in Ethiopia: Possible link of EthHIV-1 $C^{\prime}$ to subtype $C$ sequences from the high-prevalence epidemics in India and Southern Africa. AIDS Res Hum Retroviruses 2003, 19:999-1008.

24. Abebe A, Pollakis G, Fontanet AL, Fisseha B, Tegbaru B, Kliphuis A, Tesfaye G, Negassa H, Cornelissen M, Goudsmit J, Rinke De Wit TF: Identification of a genetic subcluster of HIV type 1 subtype C ( $C^{\prime}$ ) widespread in Ethiopia. AIDS Res Hum Retroviruses 2000, 16:1909-1914.

25. Abebe A, Lukashov W, Rinke De Wit TF, Fisseha B, Tegbaru B, Kliphuis A, Tesfaye G, Negassa H, Fontanet AL, Goudsmit J, Pollakis G: Timing of the introduction into Ethiopia of subcluster $C^{\prime}$ of HIV type 1 subtype C. AIDS Res Hum Retroviruses 2001, 17:657-661.

26. Ayele W, Mekonnen Y, Messele T, Mengistu Y, Tsegaye A, Bakker M, Berkhout B, Dorigo-Zetsma W, Wolday D, Goudsmit J, Coutinho R, De Baar M, Paxton W, Pollakis G: Differences in HIV Type 1 RNA plasma load profile of closely related cocirculating Ethiopian subtype $C$ strains: $C$ and $C^{\prime}$. AIDS Res Hum Retroviruses 2010, 26:805-813.

27. De Baar M, Abebe A, Kliphuis A, Tesfaye G, Goudsmit J, Pollakis G: HIV Type $1 \mathrm{C}$ and $\mathrm{C}^{\prime}$ subclusters based on long terminal repeat sequences in the Ethiopian HIV type 1 subtype C epidemic. AIDS Res Hum Retroviruses 2002, 19:917-922

doi:10.1186/1756-3305-7-204

Cite this article as: Mulu et al.: Triple NF-kB binding sites and LTR sequence similarities in HIV-1C isolates irrespective of helminth co-infection. Parasites \& Vectors 2014 7:204.

\section{Submit your next manuscript to BioMed Central and take full advantage of:}

- Convenient online submission

- Thorough peer review

- No space constraints or color figure charges

- Immediate publication on acceptance

- Inclusion in PubMed, CAS, Scopus and Google Scholar

- Research which is freely available for redistribution 